07

\title{
Технологические основы формирования микросетчатых прозрачных электродов при помощи самоорганизованного шаблона и исследование их свойств
}

\author{
(C) А.С. Воронин ${ }^{1}$, М.М. Симунин ${ }^{1,2}$, Ю.В. Фадеев ${ }^{1}$, Ф.С. Иванченко ${ }^{1,2}$, Д.В. Карпова ${ }^{1}$, \\ И.А. Тамбасов ${ }^{3}$, С.В. Хартов ${ }^{1}$ \\ ${ }^{1}$ Красноярсий научный центр СО РАН, ФИЦ КНЦ СО РАН, Красноярск, Россия \\ ${ }^{2}$ Сибирский федеральный университет, Красноярск, Россия \\ ${ }^{3}$ Институт фризики им. Л.В. Киренского СО РАН, Красноярск, Россия \\ E-mail: a.voronin1988@mail.ru
}

Поступило в Редакцию 5 декабря 2018 г.

В окончательной редакции 9 января 2019 г.

Принято к публикации 10 января 2019 г.

\begin{abstract}
Представлены результаты исследования физических свойств микросетчатых прозрачных электродов на гибкой подложке, полученных с использованием в качестве шаблона контролируемым образом растресканных слоев кремнезема. Впервые предложен комбинированный подход к управлению параметрами микросетчатой структуры (ширина трещины и размер ячейки) с помощью варьирования $\mathrm{pH}$ и толщины слоя золя. На основе описанного подхода получены прозрачные электроды с поверхностным сопротивлением $4.1 \Omega / \mathrm{sq}$ при прозрачности 85.7\%. Микросетчатые электроды характеризуются линейным оптическим пропусканием в видимом и ИК-диапазонах, что открывает перспективы для их применения в оптоэлектронике.
\end{abstract}

DOI: 10.21883/PJTF.2019.07.47542.17626

Прозрачным электродам на гибком полимерном носителе в литературе уделено большое внимание в связи с их важностью для гибкой электроники, органических и гибридных солнечных батарей, неорганических (LED) и органических светодиодов (OLED). Помимо использования для задач оптоэлектроники прозрачные электроды применяются как пленочные нагреватели и антиобледенительные покрытия. К основным решениям в данной области помимо прозрачных проводящих оксидов традиционно относятся пленки углеродных нанотрубок [1], графен [2], металлические нанопроволоки [1], а также металлические микро- и наносетки, полученные при помощи процессов фото- [3] и импринт-литографии [4]. C функциональной точки зрения металлические сетки представляют наибольший интерес за счет сочетания низкого поверхностного сопротивления менее $3-5 \Omega$ /sq и прозрачности более $85 \%$ [5], а также устойчивости к механическим деформациям и высоким температурам эксплуатации. С экономической точки зрения стандартные литографические подходы экономически неэффективны, поэтому приоритет имеют методики формирования металлических сеток, базирующиеся на процессах самоорганизации [5-8].

В работе [9] и независимо в [10,11] продемонстрирована возможность использования растресканных гелевых слоев в качестве шаблонов для получения микросетчатых прозрачных электродов. Главным достоинством метода является возможность низкозатратного формирования шаблона в roll-to-roll процессе. Предлагаемый технологический процесс состоит из четырех основных этапов. На первом этапе производится нанесение жидкого слоя золя. Второй этап - сушка слоя на воздухе с целью испарения дисперсионной среды с последующим растрескиванием геля. Третий этап - напыление металлических пленок на полученные шаблоны. Четвертый этап - удаление ячеек шаблона посредством жидкостной отмывки и сушка [9].

Задача настоящей работы состоит в разработке нового подхода к управлению геометрией трещинообразования за счет вариации параметров золя кремнезема и изучении влияния геометрических параметров самоорганизованного шаблона на оптоэлектронные параметры микросетчатых покрытий.

Для получения золей кремнезема исходные реагенты - тетраэтоксисилан (TEOS, $\left.\left(\mathrm{C}_{2} \mathrm{H}_{5} \mathrm{O}\right)_{4} \mathrm{Si}\right)$, этанол $\left(\mathrm{C}_{2} \mathrm{H}_{5} \mathrm{OH}\right)$, деионизованная вода - смешивались в соотношении $3: 2: 2$, затем по каплям добавлялась $\mathrm{HCl}$, катализирующая гидролиз TEOS. Величина $\mathrm{pH}$ золей составила 1, 1.5 и 2 соответственно. Золи наносились на подложки из полиэтилентерефталата (PET, HiFi, Japan, толщина $100 \mu \mathrm{m})$ при помощи стержня Мейера. Толщина слоя составляла 36.6 и $25.2 \mu \mathrm{m}$. Затем слои высушивались на воздухе в течение $25 \mathrm{~min}$ при относительной влажности $35-40 \%$, что обеспечивало их полное растрескивание. Морфология шаблонов изучалась при помощи средств оптической микроскопии. Статистическая обработка шаблонов производилась по выборке из десяти изображений. Напыление серебра на шаблоны выполнялось магнетронным методом, толщина напыления составляла 100-300 nm. „Lift-off“ удаление кремнеземного шаблона осуществлялось в $0.1 \mathrm{M}$ растворе $\mathrm{NaOH}$ в течение $3 \mathrm{~min}$. Пропускание прозрачных электродов измерялось в диапазоне длин волн 400-1500 nm при помощи спектрофотометра Shimadzu 
$a$

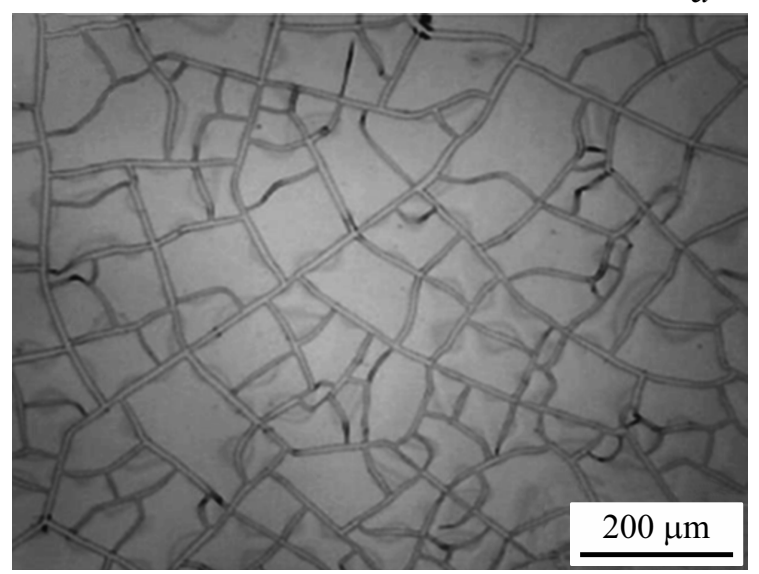

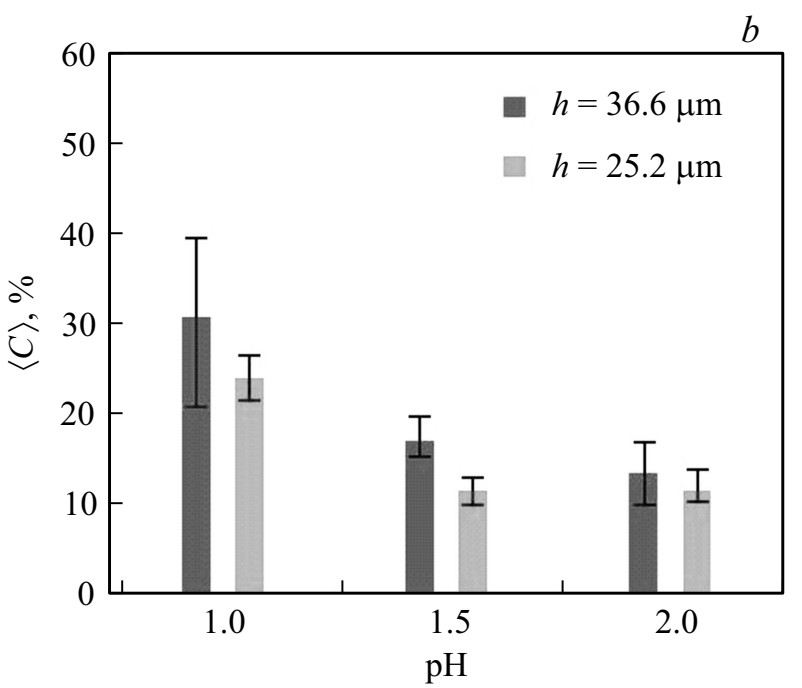

Рис. 1. $a-$ изображение самоорганизованного шаблона на основе золя кремнезема с $\mathrm{pH}=1.5$ и толщиной слоя $36.6 \mu$ m; $b$ - зависимость средней доли площади, занимаемой сеткой трещин, от величины $\mathrm{pH}$ и толщины слоя золя.
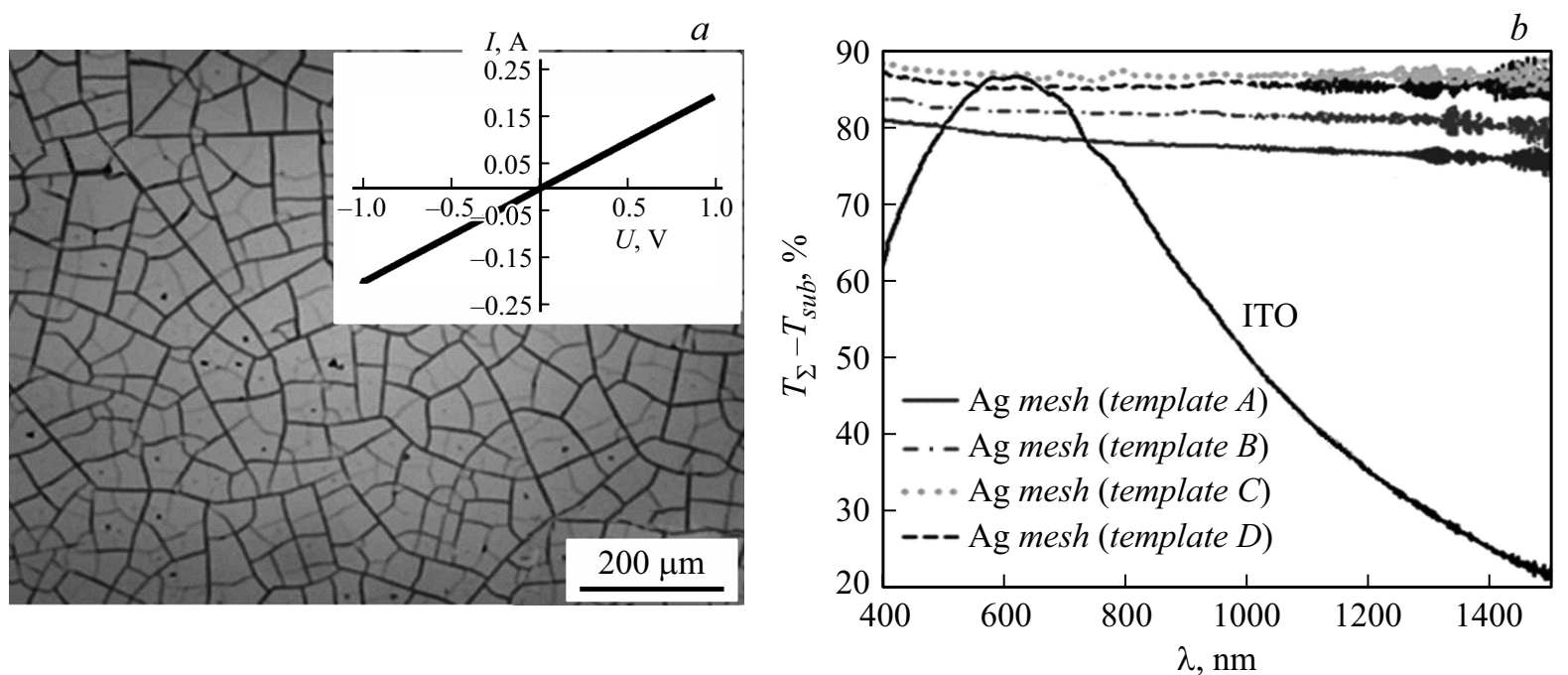

Рис. 2. $a-$ изображение микросетки (шаблон $C$ ) и ее вольт-амперная характеристика (на вставке); $b-$ спектральное оптическое пропускание серебряных микросеток на основе всей выборки шаблонов.

UV-3600 (Japan). Поверхностное сопротивление и вольтамперные характеристики измерялись по двухэлектродной методике на базе установки ИППП 1.

Растрескивание слоя геля на подложке обусловлено противоположно направленными силами, возникающими в процессе его сушки: одна сила, обусловленная уплотнением геля, стремится механически сжать слой в плоскости подложки, а другая (сила адгезии геля к подложке) препятствует этому. В результате в какойто момент времени слою становится энергетически выгодно растрескаться $[12,13]$. Микроскопическим механизмом возникновения механических напряжений в гелевом слое является избыточное капиллярное давление, увеличивающееся в процессе уплотнения геля [13].

Исходя из данных соображений можно предположить, что основным подходом к управлению геометрией тре- щинообразования является изменение толщины жидкого слоя. Другим является контроль капиллярного давления в пористой структуре. Величина $\mathrm{pH}$ среды представляет собой ключевой параметр, определяющий морфологию продуктов реакции. Увеличение $\mathrm{pH}$ способствует уменьшению длины цепей поликремниевой кислоты, что позволяет увеличивать пористость геля, а следовательно, и капиллярное давление в нем [13].

На рис. 1, $a$ показано изображение растресканной пленки кремнезема с $\mathrm{pH}$ золя 1.5 и толщиной слоя $36.6 \mu \mathrm{m}$. Статистический анализ микрофотографий показал следующее: увеличение $\mathrm{pH}$ золя с 1 до 2 при вариации толщины пленки золя позволяет уменьшать средний размер ячейки от $97.5 \pm 49.5 \mu \mathrm{m} \quad(\mathrm{pH}=1 ; 36.6 \mu \mathrm{m})$ до $40.1 \pm 17.9 \mu \mathrm{m}(\mathrm{pH}=2 ; 25.2 \mu \mathrm{m})$. Параллельно с размером ячейки уменьшается средняя ширина трещины 

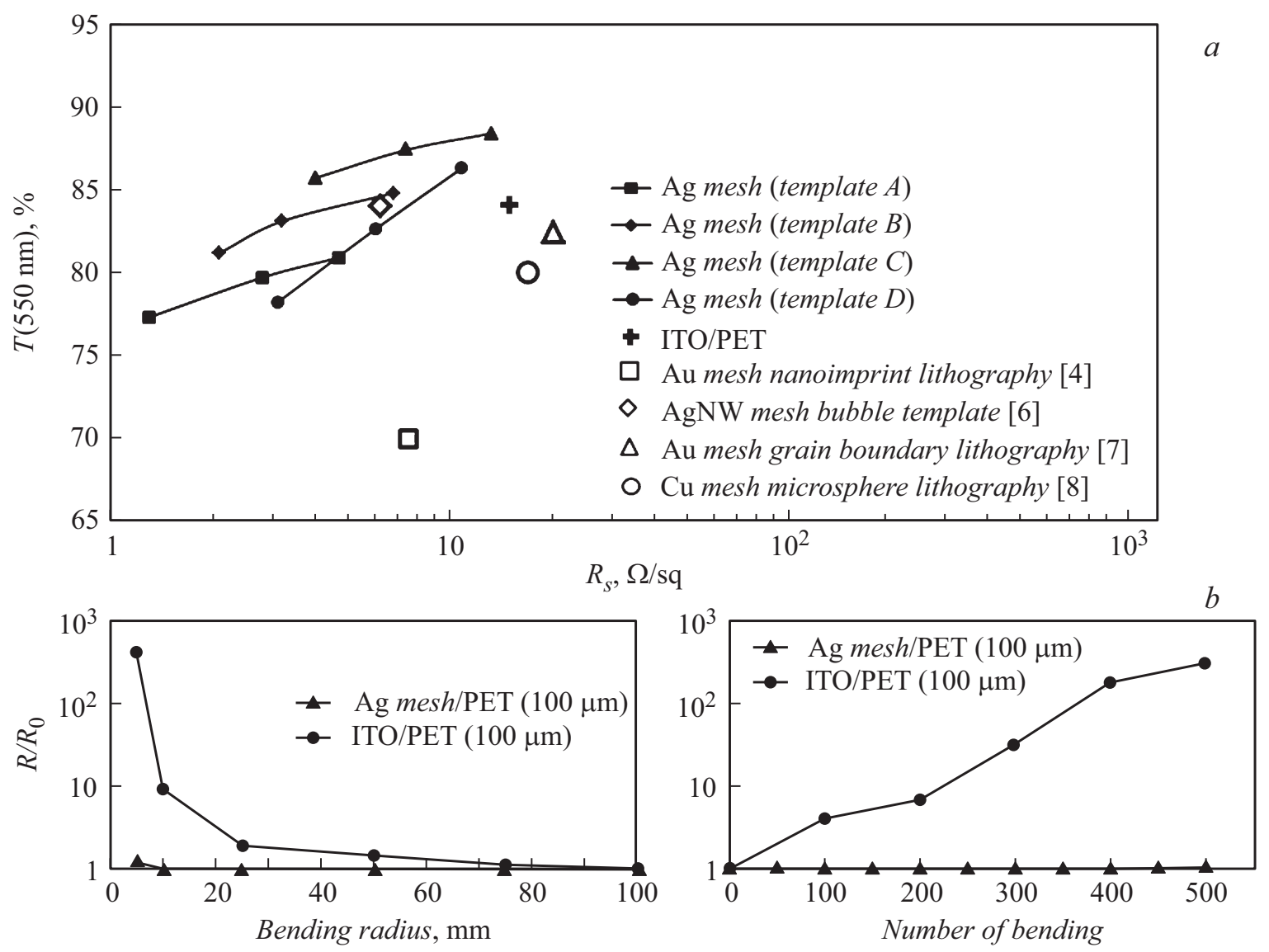

Рис. 3. $a-$ зависимость оптической прозрачности от величины поверхностного сопротивления для микросеток различной толщины и сетчатых покрытий, полученных на основе наиболее перспективных методик, использующих процессы самоорганизации [6-8]; $b$ - зависимости нормированного поверхностного сопротивления микросетки и ITO от радиуса изгиба (слева) и количества циклов изгиба (справа).

от $18.8 \pm 5.1 \mu \mathrm{m}(\mathrm{pH}=1 ; 36.6 \mu \mathrm{m})$ до $2.4 \pm 0.7 \mu \mathrm{m}$ $(\mathrm{pH}=2 ; 25.2 \mu \mathrm{m})$. Комплексное управление параметрами позволяет варьировать долю площади, занимаемую сеткой трещин, от $11.1 \pm 1.5$ до $34.3 \pm 9.1 \%$ (рис. $1, b$ ).

Прозрачные электроды формировались при помощи самоорганизованных шаблонов с долей площади, занимаемой сеткой трещин, менее $20 \%$ : шаблон $A(\mathrm{pH}=1.5$; $36.6 \mu \mathrm{m})$, шаблон $B \quad(\mathrm{pH}=2 ; 36.6 \mu \mathrm{m})$, шаблон $C$ $(\mathrm{pH}=1.5 ; 25.2 \mu \mathrm{m})$, шаблон $D(\mathrm{pH}=2 ; 25.2 \mu \mathrm{m})$. Изображение микросетки, полученной на основе шаблона $C$, показано на рис. 2, $a$. Спектральные зависимости оптического пропускания серебряных микросеток толщиной $100 \mathrm{~nm}$ на подложках РЕТ для описанной выборки шаблонов в сравнении с данными для образца коммерческого оксида индия-олова (ITO) (Mianyang Prochema, $15 \Omega / \mathrm{sq})$ приведены на рис. 2, $b$. Френелевское отражение от границ подложки РЕТ вычиталось из спектров полного пропускания и составляло $\sim 10 \%$. Прозрачность микросеток определяется коэффициентом заполнения поверхности металлом. В силу рассматриваемого механизма прозрачности спектр линеен во всем диапазоне. Снижение прозрачности ITO в ИК-диапазоне обусловлено отражением излучения плазмой носителей заряда [14], данный тезис справедлив и для других оксидов, например $\mathrm{ZnO}: \mathrm{Al}, \mathrm{SnO}_{2}: \mathrm{F}$ и т.д. Линейность пропускания и вольт-амперной характеристики (вставка на рис. 2,a) делает металлические микросетки перспективными прозрачными электродами для оптоэлектронных приложений, работающих в широком диапазоне длин волн. Также следует отметить, что, варьируя тип металла, можно управлять величиной работы выхода электрода в широком диапазоне энергий.

На рис. 3, а представлена зависимость оптического пропускания на длине волны $550 \mathrm{~nm}$ от величины поверхностного сопротивления для микросеток толщиной от 100 до $300 \mathrm{~nm}$. На основе описанной выше выборки самоорганизованных шаблонов видно, что поверхностное сопротивление снижается пропорционально увеличению толщины микросетки. При толщине серебра $300 \mathrm{~nm}$ на основе шаблона $C$ сформирована микросетка с поверхностным сопротивлением $4.1 \Omega / \mathrm{sq}$ при прозрачности $85.7 \%$. Наименьшим поверхностным сопротивлением характеризуется микросетка, полученная на основе шаблона $A$ с толщиной серебра $300 \mathrm{~nm}(1.3 \Omega / \mathrm{sq}$, прозрачность микросетки составила 77.3\%), так как ему отвечает максимальный коэффициент заполнения поверхности (рис. 3,a). Оптоэлектронные параметры коррелируют с геометрическими характеристиками шаб- 
лона. Зависимость прозрачности микросеток от толщины серебра обусловлена стохастической структурой шаблонов, где наряду с крупными ячейками присутствуют мелкие (размером 5-15 $\mu \mathrm{m}$ ). Оптические свойства сеток с малым размером ячейки за счет дифракционных эффектов имеют сильную зависимость от толщины металла [3]. Сравнение эксплуатационных характеристик микросетчатых покрытий и сетчатых покрытий, полученных с помощью наиболее актуальных методик, базирующихся на процессах самоорганизации [6-8], показывает перспективность предлагаемого подхода (рис. 3,a).

Устойчивость микросеток к изгибу существенно выше, чем у пленки ITO. При радиусе изгиба $5 \mathrm{~mm}$ микросетка (шаблон $C$, толщина серебра $200 \mathrm{~nm}$ ) увеличивает свое сопротивление на $30 \%$ (рис. $3, b$ ). Рост сопротивления коммерческого электрода ITO в этих же условиях превысил 1000\%. ITО в условиях деформации подложки, обусловленной скольжением макромолекул полимера, характеризуется хрупким разрушением в отличие от микросеток, характеризующихся пластической деформацией. Толщина подложки является ключевым фактором, так как она определяет величину деформации. Уменьшение толщины подложки способствует повышению устойчивости микросеток к изгибу. При циклической деформации с малым радиусом изгиба $(15 \mathrm{~mm})$ наблюдается незначительное накопление усталости в микросетчатых образцах (порядка 9\% от величины изначального сопротивления) за 500 циклов изгиба (рис. $3, b$ ). Этот факт также объясняется металлической природой микросетки и согласуется с рядом экспериментальных результатов, полученных на микро- и наносетках $[5,15]$.

Таким образом, продемонстрирована возможность управления геометрическими параметрами шаблона в широком диапазоне. В частности, показана возможность изменения площади формируемой через шаблон металлизации от 10 до $35 \%$. Предложенный метод позволяет получать покрытия, превосходящие ITO на полимерных подложках по основным эксплуатационным параметрам. Важным нюансом является универсальность методики с точки зрения выбора подложки. В частности, микросетка может быть сформирована на уже готовых кремниевых солнечных элементах, что позволит повысить эффективность токосъема.

Работа поддержана Российским фондом фундаментальных исследований (проект „мол_а“ № 18-38-00852).

\section{Список литературы}

[1] Hecht D.S., Hu L.B., Irvin G. // Adv. Mater. 2011. V. 23. N 13. P. $1482-1513$.

[2] Kim K.S., Zhao Y., Jang H., Lee S.Y., Kim J.M., Kim K.S., Ahn J.-H., Kim P., Choi J.-Y., Hong B.H. // Nature. 2009. V. 457. N 7230. P. 706-710.

[3] Ok J.G., Kwak M.K., Huard C.M., Youn H.S., Guo L.J. // Adv. Mater. 2013. V. 25. N 45. P. 6554-6561.

[4] Kang M.-G., Guo L.J. // Adv. Mater. 2007. V. 19. N 10. P. $1391-1396$.
[5] Guo C.F., Ren Z. // Mater. Today. 2015. V. 18. N 3. P. 143154.

[6] Tokuno T., Nogi M., Jiu J., Sugahara T., Suganuma K. // Langmuir. 2012. V. 28. N 25. P. 9298-9302.

[7] Guo C.F., Sun T., Liu Q., Suo Z., Ren Z. // Nature Commun. 2014. V. 5. P. 3121.

[8] Gao T., Wang B., Ding B., Lee J.-K., Leu P.W. // Nano Lett. 2014. V. 14. N 4. P. 2105-2110.

[9] Хартов С.В., Симунин М.М., Воронин А.С., Карпова Д.В., Шиверский А.В., Фадеев Ю.В. Сетчатая микрои наноструктура, в частности для оптически прозрачных проводящих покрытий, и способ ее получения. Патент РФ № 2574249. Заявл. 09.09.2013 (№ 2013141222). Опубл. 10.02.2016. Бюл. № 14.

[10] Han B., Pei K., Huang Y., Zhang X., Rong Q., Lin Q., Guo Y., Sun T., Guo C., Carnahan D., Giersig M., Wang Y., Gao J., Ren Z., Kempa K. // Adv. Mater. 2014. V. 26. N 6. P. 873-877.

[11] Gupta R., Walia S., Hösel M., Jensen J., Angmo D., Krebs F.C., Kulkarni G.U. // J. Mater. Chem. A. 2014. V. 2. N 28. P. $10930-10937$.

[12] Яхно Т.А., Яхно В.Г. // ЖТФ. 2009. Т. 79. В. 8. С. 133-141.

[13] Шабанова Н.А., Саркисов П.Д. Золь-гель технологии. Нанодисперсный кремнезем. М.: БИНОМ. Лаборатория знаний, 2012. $328 \mathrm{c}$.

[14] Naik G.V., Shalaev V.M., Boltasseva A. // Adv. Mater. 2013. V. 25. N 24. P. 3264-3294.

[15] Voronin A.S., Ivanchenko F.S., Simunin M.M., Shiverskiy A.V., Aleksandrovsky A.S., Nemtsev I.V., Fadeev Y.V., Karpova D.V., Khartov S.V. // Appl. Surf. Sci. 2016. V. 364. P. 931-937. 